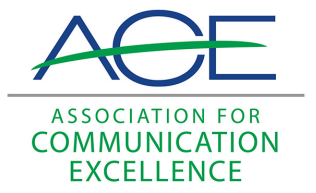

Journal of Applied Communications

\title{
Characterizing Viewpoints of Scholars in Agricultural Communications as they Relate to Research Themes in the Journal of Applied Communications: A Q Methodological Study
}

\author{
Jean A. Parrella \\ Texas A\&M University \\ Jessica R. Spence \\ Texas A\&M University \\ Tobin Redwine \\ Vivayic, Inc.
}

See next page for additional authors

Follow this and additional works at: https://newprairiepress.org/jac

Part of the Communication Commons

(c) (i) (3)

This work is licensed under a Creative Commons Attribution-Noncommercial-Share Alike 4.0 License.

\section{Recommended Citation}

Parrella, Jean A.; Spence, Jessica R.; Redwine, Tobin; and Leggette, Holli R. (2021) "Characterizing Viewpoints of Scholars in Agricultural Communications as they Relate to Research Themes in the Journal of Applied Communications: A Q Methodological Study," Journal of Applied Communications: Vol. 105: Iss. 3. https://doi.org/10.4148/1051-0834.2389

This Research is brought to you for free and open access by New Prairie Press. It has been accepted for inclusion in Journal of Applied Communications by an authorized administrator of New Prairie Press. For more information, please contact cads@k-state.edu. 


\title{
Characterizing Viewpoints of Scholars in Agricultural Communications as they Relate to Research Themes in the Journal of Applied Communications: A Q Methodological Study
}

\author{
Abstract \\ Research in agricultural communications is not guided by a national research agenda. Therefore, the \\ substantial body of research produced from scholars working in the discipline represents scattered \\ efforts. We conducted a content analysis of journal articles published in the Journal of Applied \\ Communications between 2000 and 2019 to identify the research themes that establish the discipline's \\ scholarly base. Through an examination of $n=259$ journal articles, we identified $N=27$ research themes, \\ the most prevalent of which included agriculture and media relations/practices $(f=30 ; \%=11.58)$, public \\ perceptions/understanding of agriculture and natural resources $(f=25 ; \%=9.65)$, and agricultural \\ communications academic programs and curricula $(f=21 ; \%=8.11)$. Then, we used Q methodology to \\ identify viewpoints of agricultural communications scholars (e.g., faculty, graduate students; $n=45$ ) as \\ they relate to perceptions about the importance of research. We identified four dominant viewpoints of \\ scholars in agricultural communications: Message Framing Influencers, Extension-Focused Scholars and \\ Practitioners, Discipline-Conscious Researchers, and Tech-Savvy Scholars. Together, these viewpoints \\ explained $59.43 \%$ of the study variance. Although participants who represented each of these groups had \\ unique perspectives, participants generally agreed that public perceptions/understanding of agriculture \\ and natural resources and crisis communications in agricultural communications were important \\ research themes. Likewise, they generally agreed that the role of agricultural communications \\ professional organizations, agricultural communications efforts during historical events, and agritourism \\ were not important research themes.

\section{Keywords} \\ content analysis, research agenda, research themes, Q methodology, Q sort \\ Cover Page Footnote/Acknowledgements \\ N/A \\ Authors \\ Jean A. Parrella, Jessica R. Spence, Tobin Redwine, and Holli R. Leggette
}




\section{Introduction}

With roots in rural sociology, agricultural communications emerged as a profession in the early 1800 s through the dissemination of farm information to rural audiences (Tucker et al., 2003). Thus, by nature, agricultural communications is a distinct field within the broader science communications discipline (Montemayer et al., 2020). Agricultural communicators are science communicators who disseminate information in an applied science context - agriculture (i.e., food, fiber, renewable energy, natural resources, rural development; Borchelt, 2001; Mohammed, 2020). Today, the job market for agricultural communications includes education, journalism, farm broadcasting, public relations, advertising, marketing and branding, social media, web design, photography, and videography among other strategic communication and media production roles (Irani \& Doerfert, 2013).

Agricultural communications was first introduced into higher education in 1905 as an agricultural journalism course at Iowa State University (Boone et al., 2000; Cartmell \& Evans, 2013; Duncan, 1957; Irlbeck \& Buck, 2017; Tucker et al., 2003). Three years later, the University of Wisconsin established the first agricultural journalism department, and Iowa State University offered the first four-year curriculum in 1920 (Cartmell \& Evans, 2013). Since then, agricultural journalism as an academic discipline has evolved significantly (Cartmell \& Evans, 2013; Tucker et al., 2003). Part of this evolution was documented in the 1970s when the discipline became more commonly referred to as "agricultural communications" (Cartmell \& Evans, 2013). Although it is unclear exactly how many agricultural communications programs exist across the U.S., Cartmell and Evans identified 45 in 2013 and Miller et al. identified 40 in 2015. This is a documented increase from the 26 programs that Reisner identified in 1990 and the 30 programs that Doerfert and Cepica identified in 1991. Fast forward to 2020, Texas A\&M University, University of Wisconsin-Madison, and Texas Tech University awarded the most agricultural communications degrees annually (Data USA, n.d.).

The scholarly base of agricultural communications has grown in tandem with the number and size of academic programs (Corder \& Irlbeck, 2018). Faculty members among the pioneers of agricultural communications did not have a research appointment associated with their position descriptions (Miller et al., 2015). The first attempt to emphasize and improve research in the discipline was in the early 1950s through The National Project in Agricultural Communications (NPAC), a professional development initiative funded by the Kellogg Foundation (Association for Communication Excellence, n.d.). In 1954, NPAC's research director developed an agricultural communications agenda aimed to accomplish five goals, including those to identify who is conducting research relevant to agricultural communications, to encourage better and increased research in agricultural communications, and to support the application of agricultural communications research results (Cartmell \& Evans, 2013). In 1960, near the end of the five-year project, scholarly output soared at an all-time high, and national awareness of agricultural communications research increased (Cartmell \& Evans, 2013).

After 1960, leaders in the discipline continued to emphasize the need for agricultural communications scholars to conduct research (Cartmell \& Evans, 2013). Along with the growth of agricultural knowledge in the 1970s came the need of agricultural communications research programs to deliver more specialized knowledge to larger audiences (Cartmell \& Evans, 2013). In addition, during this time, agricultural communications programs began to focus on students' skill development and strategic communication (i.e., public relations, marketing, advertising), resulting in research to examine emerging communication technologies and changes in audience 
reception (Cartmell \& Evans, 2013; Simon et al., 2003). Thus, the name "agricultural communications" was officially chosen in the 1970s to be more representative of a growing skill set that expanded far beyond the scope of journalism (Cartmell \& Evans, 2013). As a result of this growth, the amount and nature of agricultural communications research became more distinct in the 1980s when the discipline's body of literature (i.e., conference proceedings, research reports, newspapers, magazines, journals) grew "at the rate of about $14 \%$ annually" (Cartmell \& Evans, 2013; Zumalt, 2007, p. 48).

The Journal of Applied Communications $(J A C)$ became the designated journal for agricultural communications research in 1990 (Cartmell \& Evans, 2013; Edgar et al., 2009; Irani \& Doerfert, 2013; Naile et al., 2010; Zumalt, 2007). Now that members of the discipline had a consistent place to publish agricultural communications research and individual faculty were developing lines of inquiry within the discipline, scholars began conducting journal reviews to examine the scholarly base of the discipline. In 2002, Williams and Woods reviewed journal articles published in JAC between 1992 and 2001 and, although the number they reviewed is unclear, some of the most common research themes they identified were information technology, electronic media, communications management, media relations, professional development, and distance education. Four years later, Miller et al. (2006) examined journal articles published between 2000 and $2004(n=56)$, identifying communications management, information technology, media relations, distance education, and professional development as research themes. In 2009, Edgar et al. identified a variety of agricultural communications research themes and methodologies in journal articles published between 1997 and $2006(n=91)$. Among the most common research themes were information sources and technology, communication management, communications of scholarship, biotechnology communications, media relations, and distance education (Edgar et al., 2009). Most of these journal articles utilized quantitative methodologies, including surveys and content analyses (Edgar et al., 2009).

In 2010, Naile et al. conducted a review of journal articles published between 1990 and $2006(n=222)$ and identified the types of articles, frameworks, and methodologies used. Threequarters of the journal articles examined were research articles, most of which were guided by conceptual frameworks and primarily used surveys, mixed methods, and content analyses (Naile et al., 2010). Most recently in 2016, Williford et al. reviewed agricultural communications literature published in $J A C$ and by other professional organizations (i.e., the American Association of Agricultural College Editors; the Association for Communication Excellence in Agriculture, Natural Resources, and Life and Human Sciences) between 1968 and 2015 ( $n=$ 685). The most recurrent research themes they identified included channel development, use, or research (i.e., radio, print, television, web); consumers/publics (i.e., messaging, perceptions); educating professionals; journalism; higher education; and research analyses (Williford et al., 2016).

Baker and King (2017) also conducted a review of journal articles published in JAC between 1995 and $2015(n=336)$, but instead of examining research themes or methodologies, they determined the theories and models that had been used in agricultural communications research. As a result, they identified 87 theories and models, only 11 of which had been used five or more times (Baker \& King, 2017). In addition, only $35 \%$ of the journal articles in their sample included a theory or model, most of which used the theory or model to inform the study, rather than to test or build theory (Baker \& King, 2017). These findings indicate that a statement made by Evans in his 2006 commentary held true 11 years later, and likely still holds true in 2020: "there is no integrated theoretical base for agricultural communications" (p. 16). Evans (2006) 
and Baker and King (2017) highlighted the critical need for increased theoretical rigor in agricultural communications.

In 2016, however, Rodriguez et al. took a different approach to analyzing journal articles published in JAC to determine how well the content reflected the research priority areas outlined in the National Research Agenda (NRA): Agricultural Education and Communication, 20072010 (Osborne, n.d.). The NRA identified four priority research areas (RPAs) important to the future of agricultural communications: 1) "Enhance decision-making within the agricultural sectors of society;" 2) "Within and among societies, aid the public in effectively participating in decision making related to agriculture;" 3 ) "Build competitive societal knowledge and intellectual capabilities;" and 4) "Develop effective agricultural work forces for knowledgebased societies" (Osborne, n.d., p. 5). Rodriguez et al. (2016) found that, although they noticed a lack of research addressing the four RPAs, journal articles published in JAC between 2008 and $2015(n=129)$ reflected the first RPA more than the others.

The 2007-2010 NRA was the first integrative framework to guide the diverse body of research in agricultural communications and some would say the last because the subsequent NRAs did not include the words "agricultural communications" in the title or specificity to the discipline (e.g., Doerfert's [2011] National Research Agenda: American Association for Agricultural Education's Research Priority Areas for 2011-2015 and Roberts et al.'s [2016] American Association for Agricultural Education National Research Agenda 2016-2020; Doerfert, 2011). Although these research agendas reference agricultural communications as a dimension of a larger discipline inclusive of "agricultural leadership, school-based agricultural education, extension and outreach education, and agricultural education," they do not contain research priority areas or research questions specific to agricultural communications (Doerfert, 2011 , p. 6). Instead, they suggest research in agricultural communications be integrated with research from the other sub-disciplines, similar to Tucker et al. (2003), who suggested that research in agricultural communications should involve collaborations with other academic departments (e.g., agricultural education) and industry professionals.

Although this integrative approach to research has value, agricultural communications scholars recognize developing a research agenda specific to agricultural communications would help enhance departmental status and academic appointments (Cartmell \& Evans, 2013). Yet, the discipline still lacks a current research agenda despite researchers' recommendations (Irlbeck \& Buck, 2017). Even though no current research agenda exists, scholars continue to conduct a substantial amount of research within agricultural communications (Miller et al., 2015). Thus, it is important that research explores the scholarly base of agricultural communications as it progresses and its scholars' viewpoints about research areas that should be prioritized. Though many studies have explored the scholarly base of agricultural communications, viewpoints were not previously explored (Baker \& King, 2017; Edgar et al., 2009; Miller et al., 2006; Naile et al., 2010; Rodriguez et al., 2016; William \& Woods, 2002; Williford et al., 2016).

\section{Conceptual Framework}

Theories relevant to agricultural communications "grow deep, spread widely, and change constantly" (Evans, 2006, p. 25). We used Edgar et al.'s (2009) conceptual model as the basis for the study (see Figure 1). Edgar et al. (2009) used previous research "from integrated specialization areas supporting the big umbrella of agricultural education" to develop the model (p. 23). In essence, the model depicts agricultural communications as a specialized area 
supporting agricultural education. The scholarship supporting agricultural communications and every other area of specialization can be understood by conducting content analyses of research themes, prolific authors, and research methods published within discipline-specific journal articles. Thus, this model is relevant to the study because we conducted a content analysis of research themes published in JAC between 2000 and 2019 to understand the scholarly base supporting the discipline at this point in time. Then, using Q methodology, we identified viewpoints of agricultural communications scholars as they relate to the perceived importance of research themes within agricultural communications literature.

\section{Figure 1}

\section{Adapted from Edgar et al. 's (2009) Conceptual Model}

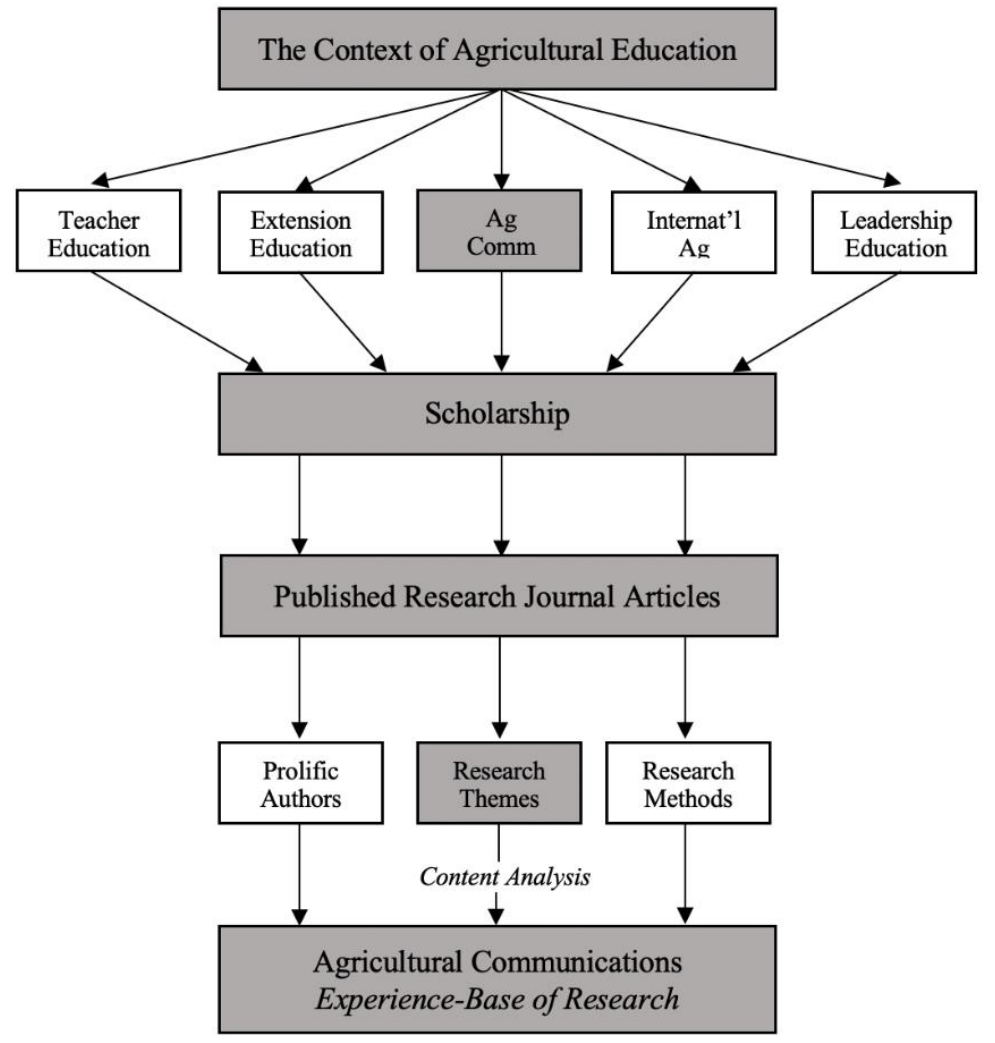

Purpose and Research Objectives

In 2007, Doerfert et al. acknowledged "past efforts reveal a scattershot pattern of research that has understandably been shaped by information needs of the place and time, individual interests, funding opportunities, and a wide array of other factors" (p. 10). Therefore, focusing and coordinating research efforts in the discipline can help broaden its impact (Doerfert, 2003; Doerfert et al., 2007; Whiting, 2002). The purpose of our study was to identify the research themes that establish the scholarly base of agricultural communications and to characterize viewpoints of agricultural communications scholars based on their perceived importance of research themes. 
Five research objectives guided the study:

1) Identify the research themes representing the scholarly base of agricultural communications;

2) Determine which of the research themes agricultural communications scholars have prioritized over the past 19 years;

3) Identify common viewpoints of agricultural communications scholars as they relate to perceptions about research importance;

4) Identify the research themes that agricultural communications scholars agree are important and not important; and

5) Determine if agricultural communications scholars' personal research practices match their beliefs about the most important research theme(s).

\section{Methodology}

We used Q methodology to identify common viewpoints of agricultural communications scholars as they relate to perceptions about research importance. Q methodology is an advantageous research method "for assessing beliefs, attitudes, or values," and it is well-suited to explore variety and diversity in understanding a particular phenomenon (Del Mol \& Buysse, 2008; Stephen, 1985, p. 194). Brown (1995) argued Q methodology is the only research method capable of so much versatility and reach. It was developed with operant subjectivity as a core component contributing to the holistic analysis of participants' views on selected topics (Watts \& Stenner, 2012). Operant subjectivity is defined as an observable behavior that "has meaning relative only to its impact upon the immediate environment" (Watts, 2011, p. 39). Thus, because no introspection is required, a Q sort is not "an expression of someone's subjectivity as such, but rather is their subjectivity, captured experimentally" (Watts, 2011, p. 39).

Often misunderstood by social scientists, Q methodology provides researchers with a rigorous means to measure humanistic elements (McKeown \& Thomas, 1988; Stephen, 1985). Edgar et al. (2009) explained that "agricultural communications research lacks diversity of research methodologies and scope, and perhaps depth and quality" (p. 30). Thus, diversity in the exploration of agricultural communications phenomena is needed to increase rigor in the field. Leggette and Redwine (2016) explained that Q methodology can be used by agricultural communications researchers in a variety of contexts and should be used to diversify research methodologies in the discipline. Therefore, in our study, we chose to use Q methodology to explore agricultural communicators' perceptions and viewpoints about the importance of research themes associated with the discipline.

\section{Concourse}

The first step to conducting a Q sort involves gathering the concourse, or the totality of beliefs, perceptions, and opinions related to the topic under investigation (van Exel \& de Graaf, 2005). The concourse can be developed, most commonly, by using interviews, observations, and peerreviewed or popular literature (van Exel \& de Graaf, 2005). For the purpose of our study, we identified relevant literature published in $J A C$ to develop the concourse. We searched the phrase "agricultural communication" in "All Issues" of JAC using newprariepress.org, which resulted in 616 journal articles. These 616 journal articles served as the concourse in our study because they represented the totality of agricultural communications research published in $J A C$. We 
conceptualized agricultural communications research as scholarship directly involving communication, or some aspect of human interaction, as it relates to "agriculture, food, natural resources and rural interests" (Zumalt, 2007, p. 44). It is likely that all journal articles focused on agricultural communications published in $J A C$ would purposefully include the phrase since it is the designated journal for such research.

\section{Q Set}

Researchers must then derive the $\mathrm{Q}$ set, or a representative sample of statements from the concourse to present to participants (Brown, 1993). To identify Q set statements, we conducted a quantitative conceptual content analysis of the peer reviewed journal articles that represented the concourse in the study because a discipline's journal articles are good indicators of research priorities in a discipline (Knight, 1984; McTavish \& Pirro, 1990). After the initial keyword search resulted in $N=616$ journal articles, we eliminated all journal articles published before 2000. This resulted in $n=351$ eligible journal articles. We eliminated articles published before 2000 because we were primarily interested in research published after the turn of the century as it is timelier. We interpreted the topic of agricultural communications research by reading the title of each eligible journal article and, if further information was needed to ensure accurate interpretation, we also analyzed the abstracts. To interpret the topic of agricultural communications research, we identified key words or phrases to determine the essence of the study. For example, "Public perceptions of..." or "Portrayal of agriculture in..." served as phrases that enabled us to interpret the research focus.

We excluded 92 journal articles for one of several reasons. First, we excluded duplicate journal articles when two of the same article existed in the pool of eligible articles. Second, we excluded journal articles that were not central to the field of agricultural communications. We decided journal articles were not central to the field when a topic related to agriculture, food, natural resources, or rural interests and a topic related to communication did not both play a role in the research. In these instances, "agricultural communication" was referenced briefly in the introduction, discussion, or author biography, but the research did not pertain directly to the field. For example, we excluded Robert and Evan's (2015) journal article entitled "Tackling Structural Format - The 'Great Unknown' in Professional Blogging' because although it may have relevant implications for agricultural communications, the publication did not involve agriculture, food, natural resources, or rural interests. The phrase "agricultural communication" only existed in the authors' biography. Third, we excluded results labeled "Editorial board, information for authors, and other front matter", "Front Matter", and "Full Issue" because they did not classify as journal articles. Therefore, after excluding 92, we used a total of $n=259$ articles to develop the Q set.

Using a Microsoft Excel spreadsheet to track data collection and analysis procedures, we recorded the type of agricultural communications research identified within each of the 259 journal articles, the number of journal articles supporting each research topic, and the citation of each journal article. We used open coding and the constant comparative method to combine similar research topics, which resulted in $N=27$ unique research themes (Glaser, 1965). These research themes represented the Q set (see Table 1).

\section{Table 1}


$Q$ Set of Research Themes $(N=27)$ and the Frequency and Percentage of Journal Articles Analyzed in JAC $(n=259)$ Supporting Each Research Theme

\begin{tabular}{lcc}
\hline Research Theme & $f$ & $\%$ \\
\hline Agriculture and media relations/practices & 30 & 11.58 \\
Public perceptions/understanding of agriculture and natural & 25 & 9.65 \\
$\quad$ resources & 21 & 8.11 \\
Agricultural communications academic programs and curricula & 17 & 6.56 \\
Role of social media in agricultural communications & 16 & 6.18 \\
Effects of message framing on consumer perceptions and behaviors & 14 & 5.41 \\
Agricultural communications students & 13 & 5.02 \\
Improving science communication efforts & 11 & 4.25 \\
Agricultural communications campaigns & 11 & 4.25 \\
Visual literacy and/or visual communication & 10 & 3.86 \\
Evaluation research in agricultural communications (including & 10 & 3.86 \\
$\quad$ communication audits) & 9 & 3.47 \\
Role of agricultural communications professional organizations & 8 & 3.09 \\
Use of rigorous research methods in agricultural communications & 8 & 3.09 \\
Communication in the Cooperative Extension System & 7 & 2.70 \\
Technology in agricultural communications & 7 & 2.70 \\
Changes and challenges in agricultural communications & 7 & 2.70 \\
Portrayal of agriculture in entertainment media & 6 & 2.32 \\
Producers' use of communication channels & 6 & 2.32 \\
Agricultural organization/producer information sources & 5 & 1.93 \\
Cooperative Extension System programming & 5 & 1.54 \\
Agricultural communications efforts during historical events & 4 & 1.16 \\
Agricultural advertising & 3 & 1.16 \\
Agritourism & 3 & 1.16 \\
Crisis communication in agricultural communications & 3 & 0.77 \\
Farm safety communication & 2 & 0.77 \\
Agroterrorism & 1 & 0.39 \\
Agricultural publication editor decision-making & & \\
\hline
\end{tabular}

\section{P Set}

In Q Method studies, the P set consists of people who can be purposively selected to match the frame of the study, ensuring each anticipated viewpoint is represented (van Exel \& de Graaf, 2005). We purposively selected the $P$ set, which consisted of agricultural communications scholars $(n=46)$ who attended an author-hosted professional development session at the National Agricultural Communications Symposium in February 2020: "Operant Subjectivity as reflection and research: What is a Q Sort and why should you care?" The scholars consisted of agricultural communications faculty and graduate students (master's and doctoral). One participant duplicated a statement in their Q sort and, therefore, was excluded from the final sample of $n=45$. Several scholars chose not to participate, so not every attendee was part of the sample. The size of the $\mathrm{P}$ set should be equal to or greater than about half the number of $\mathrm{Q}$ set 
statements to ensure proper statistical analyses can be conducted using the resulting data set (Brouwer, 1999; van Exel \& de Graaf, 2005). Therefore, the sample size $(n=45)$ was sufficient because the Q set contained $N=27$ statements.

\section{Administering the $Q$ sort}

The process of participants rating statements based on their perspectives and viewpoints is called the Q sort (Watts \& Stenner, 2012). We provided each participant with an 11-column table for sorting the $27 \mathrm{Q}$ set statements, which we printed on a 17" x 22" sheet of paper (see Figure 2). The $\mathrm{Q}$ sorting process involves participants arranging the $\mathrm{Q}$ set onto the forced distribution, which requires them to rank statements they agree with least (negative numbers) to statements they agree with most (positive numbers; Leggette \& Redwine, 2016). Each statement is coded by placement on the distribution board (Killam et al., 2013). It is important to note that the value of statements varies horizontally, whereas statements in vertical columns hold the same value. Watts and Stenner (2012) suggested using a platykurtic distribution in cases where the opinions on a subject vary widely in the population. Platykurtic distributions are comparatively flatter and less peaked than normal distributions. Therefore, we chose to design the distribution board with one available space on each end so that participants had to identify one research topic they deemed most important, and one research topic they deemed least important. To maintain confidentiality, we did not collect participant names. However, we did request they write a statement describing their personal research on the top right corner of the distribution board so that we could determine whether or not their personal research matched the research topic they deemed most important.

\section{Figure 2}

\section{Q-Sort Distribution Board}

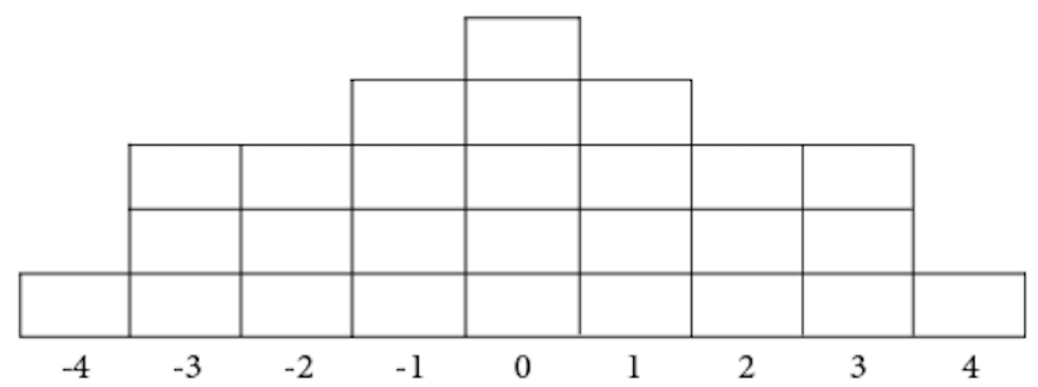

\section{Data Analysis}

We used PQMethod software to analyze the data (Killam et al., 2013). Spearman (1937) highlighted three steps to factor analysis - factor extraction, factor rotation, and factor analysis. The factors represent participant viewpoints. To prepare for data analysis, we first entered the 27 Q set statements and participants' 45 Q sorts into PQMethod.

\section{Factor Extraction}


We conducted a principal components analysis to determine the factors most closely related. Conducting a principal components analysis in PQMethod yields a table with Eigenvalues (EVs) - a number “indicative of a factor's statistical strength" (Watts \& Stenner, 2012, p. 105). Often, Q methodologists implement the Kaiser-Guttman criterion and extract factors that generate an EV greater than one (Guttman, 1954; Kaiser, 1970; Watts \& Stenner, 2012). Results from the principal components analysis generated 11 factors with EVs greater than one; however, the maximum number of factors one can extract using PQMethod is eight. Thus, we implemented additional objective criteria to decide how many factors to extract, part of which relied on researcher experience (Watts \& Stenner, 2012). As a result, we focused on a four-factor solution that explained $59.43 \%$ of the study variance because we found a natural break in the EVs associated with factor four and factor five. Therefore, we extracted four factors with EVs above three that individually explained more than $7 \%$ of the variance, which is a meaningful solution because these factors explain most of the study variance and involve a set of factors with high EVs (Watts \& Stenner, 2012).

\section{Factor Rotation}

Next, we conducted a varimax rotation to map the positions (i.e., similarities, differences) of all Q sorts in the study as they related to the four extracted factors (Watts \& Stenner, 2012). Factor rotations reveal Q sorts that closely align with the viewpoints of each factor by creating a factor estimate- the weighted average of all Q sorts that contribute significantly to a given factor (Watts \& Stenner, 2012). Factor loading scores indicate how close the approximation is between individual Q sorts and their associated factors (Watts \& Stenner, 2012). To ensure extremely close proximity between Q sorts and their associated factors, we only included Q sorts with "a factor loading greater than 0.60 on the relevant factor and factor loadings of less than 0.40 on all other factors" (Jordan et al., 2005; Watts \& Stenner, 2012, p. 131). We implemented the 60:40 criteria consistently across factors.

\section{Factor Analysis}

Finally, we conducted the final factor analysis of all the Q sorts we collected. To interpret the final analysis and explain the viewpoints of scholars in agricultural communications, we relied on $z$ scores (i.e., standard scores derived from the total weighted scores for each $\mathrm{Q}$ sort contributing to the factor estimates), Q sort values (i.e., statements' placement on the distribution board), distinguishing statements (i.e., statements that participants, who loaded on a specific factor, placed in a significantly different location on the distribution board compared to all participants who loaded on other factors), and factor arrays (i.e., best estimates of a factor's placement of statements representing their viewpoint; Watts \& Stenner, 2012). Using these criteria, we created a descriptive label for each factor that explained the viewpoint of participants who represented each factor.

\section{Trustworthiness of Conceptual Content Analysis}

We employed several strategies to ensure the conceptual content analysis we conducted to develop the Q set was trustworthy. We considered the four criteria of trustworthinesscredibility, transferability, dependability, and confirmability - to yield confidence in the data 
(Lincoln \& Guba, 1985). To achieve credibility, we implemented investigator triangulation and relied on intercoder reliability by involving two researchers in the data collection and data analysis processes to compare ideas and interpretations (Lombard et al., 2002; Patton, 2002). Specifically, the lead researcher initially interpreted the topic of agricultural communications research in each study included in the dataset. Upon completion, another researcher reviewed the work completed by the lead researcher and agreed or disagreed with their decisions. The lead researcher also completed open coding analysis procedures to develop research themes prior to another researcher reviewing and contemplating their decisions. We resolved discrepancies during each phase of analysis through conversation. To achieve transferability, we used descriptive statements to the label the research themes - the Q set statements - to avoid confusion as to which research topics they encompass. Finally, to achieve a dependable and confirmable study, we recorded an audit trail to document all thinking process and used peer debriefing to challenge each other's assumptions and interpretations of the data (Creswell \& Miller, 2000; Creswell \& Poth, 2018).

Researcher subjectivity can affect the outcomes of a qualitative study (Preissle, 2015). Therefore, it is necessary to disclose information about our professions and perspectives. The lead author is a graduate student studying agricultural communications and a graduate research assistant funded on a large-scale USDA project. In terms of the research themes identified as a result of the content analysis, her research aligns with Effects of message framing on consumer perceptions and behaviors. At the time of our study, the second author was also a graduate student studying agricultural communications but now works as an agricultural communicator for an international organization. Her research is actively focused within Visual literacy and/or visual communication. The third author earned graduate degrees in agricultural communications and, at the time of the study, was a faculty member in agricultural communications and journalism with a research agenda focused on Visual literacy and/or visual communication. However, he is now an agricultural communicator for an international organization. The fourth author earned graduate degrees in agricultural communications and is a faculty member in agricultural communications and journalism with a primary research appointment. Her research focuses on Improving science communication efforts. Therefore, as scholars in the discipline, we were familiar with the scholarly base of agricultural communications and two of us have published journal articles included in the dataset.

\section{Validity and Reliability of $Q$ Method}

Although Q methodology does not fit within the paradigms of qualitative or quantitative research, validity and reliability are appropriate psychometric properties but assessed differently (Ramlo \& Newman, 2011; Wratten et al., 2019). Q sorts are considered valid expressions of participants' point of view (Wratten et al., 2019). In addition, generalizations in Q methodology are based on theoretical implications and the validity of identified opinions or concepts (Valenta \& Wigger, 1997). The use of investigator triangulation and intercoder reliability ensured the validity of research themes in the $\mathrm{Q}$ set, allowing us to generalize the results. It is important to note, however, that rather than making inferences from a sample to a population, Q methodology can transfer perspectives of an idea (Leggette \& Redwine, 2016). Therefore, generalizing results in a Q method study is not always intended (Wratten et al., 2019). For a Q method study to be reliable, the composite reliability of each factor should be above 0.80 (Watts \& Stenner, 2012). The four factors that we focused on had composite reliabilities that met this standard and, 
therefore, achieved reliability (see Table 2). In addition, evidence shows that Q methodology should have an acceptable test-retest reliability (Dennis, 1992). We also applied the concept of transferability because it is relevant to Q methodology in the sense that researchers must develop a persona through careful consideration of the data. Transferability is enhanced through purposive sampling (Polit \& Beck, 2010).

\section{Limitations}

This study has three limitations. First, we used "agricultural communication" as the single search term to generate the dataset used to conduct the content analysis. Additional search terms may have yielded a different dataset and, therefore, different results from the content analysis and Q sort. Second, we sorted the literature into categories using our interpretation of the research focus based on article titles and abstracts. Replication of this study might be difficult because different interpretations may yield different results. Third, to complete the Q sort analysis, we focused on a four-factor solution that explained $59.43 \%$ of the study variance, with $40.57 \%$ of the variance unaccounted for in our results. Thus, not all types of agricultural communications scholars are represented and understood by our study.

\section{Results}

We conducted a quantitative conceptual content analysis to achieve research objectives one and two. The $N=27$ research themes we identified in journal articles published in JAC between 2000 and 2019 represented the Q set (see Table 1). If research themes were supported by a minimum of 10 journal articles, then we deemed that area of research as having been prioritized by agricultural communications scholars (see Table 2).

\section{Table 2}

Research Themes Prioritized by Agricultural Communications Scholars $(N=11)$

\begin{tabular}{lcc}
\hline Research Theme Priority & $f$ & $\%$ \\
\hline Agriculture and media relations/practices & 30 & 11.58 \\
Public perceptions/understanding of agriculture and natural & 25 & 9.65 \\
$\quad$ resources & 21 & 8.11 \\
Agricultural communications academic programs and curricula & 17 & 6.56 \\
Role of social media in agricultural communications & 16 & 6.18 \\
Effects of message framing on consumer perceptions and behaviors & 14 & 5.41 \\
Agricultural communications students & 13 & 5.02 \\
Improving science communication efforts & 11 & 4.25 \\
Agricultural communications campaigns & 11 & 4.25 \\
Visual literacy and/or visual communication & 10 & 3.86 \\
Evaluation research in agricultural communications (including & 10 & 3.86 \\
$\quad$ communication audits) & & \\
Role of agricultural communications professional organizations & &
\end{tabular}


To achieve research objective three, we extracted four factors. Each has between four and nine defining variables, has a composite reliability of above 0.80, and represents a common viewpoint (see Table 3). Factor Q sort values for each statement indicate the location participants (representing the four factors) placed the statement on the distribution board, indicative of its perceived value (see Table 4).

Table 3

Factor Characteristics

\begin{tabular}{lcccc}
\hline Characteristics & \multicolumn{3}{c}{ Factors } \\
\cline { 2 - 5 } & 1 & 2 & 3 & 4 \\
\hline No. of Defining Variables & 9.00 & 4.00 & 8.00 & 6.00 \\
Average Reliability Coefficient & 0.80 & 0.80 & 0.80 & 0.80 \\
Composite Reliability & 0.97 & 0.94 & 0.97 & 0.96 \\
Standard Error of Factor Z Scores & 0.16 & 0.24 & 0.17 & 0.20 \\
\hline
\end{tabular}

Table 4

Factor Q Sort Values for Each Statement

\begin{tabular}{|c|c|c|c|c|c|}
\hline Statement No. & Statement & \multicolumn{4}{|c|}{ Factor Arrays } \\
\hline & & 1 & 2 & 3 & 4 \\
\hline 1 & $\begin{array}{l}\text { Communication in the Cooperative Extension } \\
\text { System }\end{array}$ & -3 & 3 & 2 & -1 \\
\hline 2 & Agriculture and media relations/practices & 2 & 0 & 0 & 3 \\
\hline 3 & Visual literacy and/or visual communication & 0 & 0 & 1 & 3 \\
\hline 4 & Cooperative Extension System programming & -3 & 1 & 0 & -3 \\
\hline 5 & $\begin{array}{l}\text { Agricultural communications academic programs } \\
\text { and curricula }\end{array}$ & 1 & -2 & 3 & 0 \\
\hline 6 & $\begin{array}{l}\text { Changes and challenges in agricultural } \\
\text { communications }\end{array}$ & 0 & 0 & 1 & 0 \\
\hline 7 & Agroterrorism & -2 & 0 & -3 & -3 \\
\hline 8 & Agricultural advertising & 1 & -2 & -2 & 0 \\
\hline 9 & $\begin{array}{l}\text { Effects of message framing on consumer } \\
\text { perceptions and behaviors }\end{array}$ & 4 & 0 & 0 & -3 \\
\hline 10 & Producers' use of communication channels & 1 & 2 & 0 & 3 \\
\hline 11 & Portrayal of agriculture in entertainment media & 0 & -3 & -3 & 1 \\
\hline 12 & $\begin{array}{l}\text { Agriculture organization/producer information } \\
\text { sources }\end{array}$ & 0 & 2 & 0 & 1 \\
\hline 13 & $\begin{array}{l}\text { Agricultural communication efforts during } \\
\text { historical events }\end{array}$ & -3 & -1 & -2 & -2 \\
\hline 14 & Agricultural communications students & -1 & -3 & 2 & 2 \\
\hline 15 & Improving science communication efforts & 2 & 3 & 4 & 0 \\
\hline 16 & $\begin{array}{l}\text { Crisis communications in agricultural } \\
\text { communications }\end{array}$ & 3 & 4 & 1 & 2 \\
\hline
\end{tabular}


17
Best farm management practices

Farm safety communication

Role of agricultural communications professional organizations

Agricultural communications campaigns

Technology in agricultural communications

Agritourism

Agricultural editor publication decision-making

Role of social media in agricultural communications

Use of rigorous research methods in agricultural communications

Evaluation research in agricultural communications (including communication audits)

Public perceptions/understanding of agricultural and natural resources $\begin{array}{llll}-4 & -1 & -4 & 1\end{array}$

$\begin{array}{llll}-2 & 2 & -1 & -1\end{array}$

$\begin{array}{llll}-2 & -1 & -1 & -1\end{array}$

$\begin{array}{llll}2 & 1 & -1 & 0\end{array}$

$\begin{array}{llll}-1 & 1 & 1 & 4\end{array}$

$\begin{array}{llll}-1 & -3 & -1 & -1\end{array}$

$\begin{array}{llll}-1 & -4 & -3 & -4\end{array}$

$\begin{array}{llll}3 & 1 & -2 & 1\end{array}$

$\begin{array}{llll}1 & -1 & 3 & -2\end{array}$

$\begin{array}{llll}0 & -2 & 2 & -2\end{array}$

$\begin{array}{llll}3 & 3 & 3 & 2\end{array}$

\section{Factor One: Message Framing Influencers}

Factor one explained $33 \%$ of the variance, with nine defining variables, a composite reliability of 0.97, and an Eigenvalue of 14.85. Participants who represented factor one agreed the most important research themes were effects of message framing on consumer perceptions and behaviors, improving science communication efforts, and agriculture and media relations/practices. They agreed the least important research theme was communication in the Cooperative Extension System (see Table 5). Based on these distinguishing statements, we identified participants who represented factor one as Message Framing Influencers.

\section{Table 5}

Distinguishing Statements for Factor One with their Associated Q Sort Value and Z Score

\begin{tabular}{clcc}
\hline Statement No. & Statement & Q Sort Value & Z Score \\
\hline 9 & Effects of message framing on consumer & 4 & $2.23^{*}$ \\
& perceptions and behaviors & & \\
15 & Improving science communication efforts & 2 & 0.97 \\
2 & Agriculture and media relations/practices & 2 & 0.93 \\
8 & Agricultural advertising & 1 & 0.54 \\
25 & Use of rigorous research methods in agricultural & 1 & $0.41^{*}$ \\
& communication & & \\
11 & Portrayal of agriculture in entertainment media & 0 & $-0.04^{*}$ \\
26 & Evaluation research in agricultural communications & 0 & $-0.13^{*}$ \\
& (including communication audits) & & \\
21 & Technology in agricultural communications & -1 & -0.15 \\
14 & Agricultural communications students & -1 & $-0.60^{*}$ \\
23 & Agricultural editor publication decision-making & -1 & -0.76
\end{tabular}


Note. $*$ indicates statistical significance at the 0.01 alpha level. Statistical significance indicates that the placement of the statement by this group is significantly different from the placement of the statement by other groups.

\section{Factor Two: Extension-Focused Scholars and Practitioners}

Factor two explained $10 \%$ of the variance, with four defining variables, a composite reliability of 0.94, and an Eigenvalue of 4.4. Participants who represented factor two agreed the most important research themes were communication in the Cooperative Extension System and farm safety communication. They agreed the least important research themes were agricultural communications academic programs and curricula and agricultural communications students (see Table 6). As a result, we identified participants who represented factor two as ExtensionFocused Scholars and Practitioners.

\section{Table 6}

Distinguishing Statements for Factor Two with their Associated Q Sort Value and Z Score

\begin{tabular}{clcc}
\hline Statement No. & Statement & Q Sort Value & Z Score \\
\hline 1 & Communication in the Cooperative Extension & 3 & 1.52 \\
& System & 2 & $1.01^{*}$ \\
18 & Farm safety communication & 0 & $0.17^{*}$ \\
7 & Agroterrorism & -1 & $-0.35^{*}$ \\
17 & Best farm management practices & -2 & $-1.12^{*}$ \\
5 & Agricultural communications academic programs & & \\
& and curricula & -3 & $-1.52^{*}$ \\
\hline
\end{tabular}

Note. * indicates statistical significance at the 0.01 alpha level.

\section{Factor Three: Discipline-Conscious Researchers}

Factor three explained $9 \%$ of the variance, with eight defining variables, a composite reliability of 0.97, and an Eigenvalue of 4.08. Participants who represented factor three agreed the most important research themes were agricultural communications academic programs and curricula and the use of rigorous research methods in agricultural communications. They agreed the least important research theme was the role of social media in agricultural communications (see Table 7). We identified participants who represented factor three as Discipline-Conscious Researchers.

\section{Table 7}

Distinguishing Statements for Factor Three with their Associated Q Sort Value and Z Score 


\begin{tabular}{clcc}
\hline Statement No. & Statement & Q Sort Value & Z Score \\
\hline 5 & $\begin{array}{l}\text { Agricultural communications academic programs } \\
\text { and curricula }\end{array}$ & 3 & $1.35^{*}$ \\
25 & $\begin{array}{l}\text { Use of rigorous research methods in Agricultural } \\
\text { communications }\end{array}$ & 3 & $1.29^{*}$ \\
26 & $\begin{array}{l}\text { Evaluation research in agricultural communications } \\
\text { including communication audits) }\end{array}$ & 2 & $0.85^{*}$ \\
& $\begin{array}{l}\text { Communication in the Cooperative Extension } \\
1\end{array}$ & 2 & 0.83 \\
3 & $\begin{array}{l}\text { System } \\
\text { Visual literacy and/or visual communication }\end{array}$ & 1 & 0.59 \\
24 & $\begin{array}{l}\text { Producers' use of communication channels } \\
\text { Role of social media in agricultural } \\
\text { communications }\end{array}$ & -2 & $-0.38^{*}$ \\
& & $-0.90^{*}$ \\
\hline
\end{tabular}

Note. * indicates statistical significance at the 0.01 alpha level.

\section{Factor Four: Tech-Savvy Scholars}

Factor four explained $8 \%$ of the variance, with five defining variables, a composite reliability of 0.95, and an Eigenvalue of 3.41. Participants who represented factor four agreed the most important research themes were technology in agricultural communications, agriculture and media relations/practices, and visual literacy and/or visual communication. They agreed the least important research theme was effects of message framing on consumer perceptions and behaviors (see Table 8). Therefore, we identified participants who represented factor four as Tech-Savvy Scholars.

\section{Table 8}

Distinguishing Statements for Factor Four with their Associated Q Sort Value and Z Score

\begin{tabular}{rlcc}
\hline Statement No. & Statement & Q Sort Value & Z Score \\
\hline 21 & Technology in agricultural communications & 4 & $1.76^{*}$ \\
2 & Agriculture and media relations/practices & 3 & 1.46 \\
3 & Visual literacy and/or visual communication & 3 & 1.17 \\
11 & Portrayal of agriculture in entertainment media & 1 & $0.74^{*}$ \\
17 & Best farm management practices & 1 & $0.66^{*}$ \\
8 & Agricultural advertising & 0 & 0.01 \\
15 & Improving science communication efforts & 0 & $-0.13^{*}$ \\
1 & Communication in the Cooperative Extension & -1 & $-0.53^{*}$ \\
& System & -3 & $-1.44^{*}$ \\
9 & Effects of message framing on consumer & & \\
\hline
\end{tabular}

Note. $*$ indicates statistical significance at the 0.01 alpha level.

\section{Consensus Statements}


To achieve research objective four, we identified consensus statements among participants. Participants generally agreed that public perceptions/understanding of agriculture and natural resources and crisis communications in agricultural communications were important research themes. Likewise, participants generally agreed that the role of agricultural communications professional organizations, agricultural communications efforts during historical events, and agritourism were not important research themes.

\section{Participants' Personal Research}

To achieve research objective five, we asked participants to write a statement summarizing their personal research in the top right corner of their individual Q sort distribution board. Three participants did not write a statement about their research, and we chose not to report the personal research statements of $n=42$ participants to maintain confidentiality. However, we did compare participants' personal research statements with the research theme they deemed most important. Of $n=42$ participants, $n=15$ (35.7\%) did not research a topic related to the research theme they deemed most important, whereas $n=27(64.3 \%)$ provided a research statement that mirrored the research theme they deemed most important or aligned with it closely. We identified key words in participant's personal research statement and compared them to key words in the research theme to determine their alignment.

\section{Discussion and Conclusions}

Results indicate there are four dominant viewpoints of scholars in agricultural communications: Message Framing Influencers, Extension-Focused Scholars and Practitioners, DisciplineConscious Researchers, and Tech-Savvy Scholars.

Message Framing Influencers agreed it is most important to investigate the effects of message framing on consumer perceptions and behaviors, which directly relates to improving science communication efforts and agriculture and media relations/practices. Often, message framing falls under the umbrellas of science communication and media interaction. Message Framing Influencers value agricultural advertising, which, in essence, is the epitome of strategic message framing. Therefore, these scholars agreed the most important area of research in agricultural communications is investigating the effect of message framing strategies on consumer perceptions and behaviors as they relate to science and agriculture in varied contexts (i.e., media, advertising).

Results from the content analysis indicate that research on message framing, science communication, and media relations/practices have been research priorities in agricultural communications over the past two decades. Effects of message framing on consumer perceptions and behaviors, a theme similar to one identified by Williford et al. (2016), was the fifth most prevalent research theme of the $N=27$ we identified. Specifically, this theme was supported by $n$ $=16$ of the $n=259$ journal articles we examined that were published in $J A C$ between 2000 and 2019. Message framing as a research priority likely came into existence in the 1970s when agricultural communications programs expanded to include strategic communication (i.e., public relations, marketing, advertising; Cartmell \& Evans, 2013; Simon et al., 2003). This expansion spurred research that investigated changes in audience reception (Cartmell \& Evans, 2013; Simon et al., 2003), which can often be a direct result of strategically framed messages. Improving science communication efforts has also been a research priority in agricultural 
communications as $n=13$ journal articles supported the theme. Finally, agriculture and media relations/practices was the most prevalent theme we identified, supported by $n=30$ journal articles, which was similar to Williams and Woods's (2002), Miller et al.'s (2006), and Edgar et al.'s (2009) findings. Thus, it is possible that Message Framing Influencers are among the most published scholars in the discipline.

Individuals who represented factor two agreed it is most important for agricultural communications scholars to investigate communication in the Cooperative Extension System, which is opposite from Message Framing Influencers who agreed it is least important to investigate communication in the Cooperative Extension System. As a result, we identified individuals who represented factor two as Extension-Focused Scholars and Practitioners. A fundamental responsibility of those working within Extension, farm safety communication was important to Extension-Focused Scholars and Practitioners. In essence, the Cooperative Extension System is an agency established for the purpose of translating research into practice by communicating science to farmers, ranchers, and community members. Additionally, some agricultural communicators have Extension responsibilities as part of their faculty appointment. Thus, it is logical there are a group of scholars conducting research in agricultural communications who consider the functions of the Cooperative Extension System to be most important.

Despite this perceived importance, communication in the Cooperative Extension System and farm safety communication have not been a research priority because the content analysis results revealed $n=8$ journal articles supported the first theme and $n=3$ journal articles supported the second. However, both research areas align with the 2007-2010 NRA's first RPA- "Enhance decision-making within the agricultural sectors of society" (Osborne, n.d., p. 5; Rodriguez et al., 2016). Furthermore, Extension-Focused Scholars and Practitioners agreed it is least important for research in agricultural communications to focus on agricultural communications as an academic discipline, including programs, curricula, and students. These scholars likely believe the natural progression of the discipline and profession is satisfactory and, therefore, do not consider these research areas as priorities.

In opposition, individuals who represented factor three agreed it is most important for research in agricultural communications to focus on the academic discipline, as they agreed research focused on agricultural communications academic programs and curricula is most important. We labeled these individuals Discipline-Conscious Researchers because of their clear commitment to advancing the academic discipline of agricultural communications. These scholars also agreed the use of rigorous research methods in agricultural communications is of high importance, similar to the research analyses theme identified by Williford et al. (2016), which reflects their commitment not only to advancing teaching but also advancing the quality and rigor of research in the discipline.

Over the last two decades, agricultural communications academic programs and curricula has been a research priority in agricultural communications, with support from $n=21$ journal articles. This line of inquiry also aligns with the 2007-2010 NRA's fourth RPA"Develop effective agricultural work forces for knowledge-based societies" (Osborne, n.d., p. 5; Rodriguez et al., 2016). The use of rigorous research methods in agricultural communications has not been a research priority, however, as only $n=9$ journal articles supported this theme.

Similar to Extension-Focused Scholars and Practitioners, Discipline-Conscious Researchers also recognize the importance of investigating communication in the Cooperative Extension System, likely because they acknowledge the agency's connection to the discipline. 
Interestingly, Discipline-Conscious Researchers agreed it is least important for agricultural communications scholars to investigate the role of social media in agricultural communications. This came as somewhat of a surprise, given the expansion of agricultural communications programs and curricula to include social media (Irani \& Doerfert, 2013). In the current technological age, social media also play an increasingly important role in agricultural communications (Corder \& Irlbeck, 2018). Results from the content analysis indicate that research methods reflect this increasingly important role, as scholars have prioritized investigating it over the last two decades. In fact, the role of social media in agricultural communications was the fourth most prevalent research theme we identified, supported by $n=17$ journal articles. Williford et al. (2016) identified a similar theme in their content analysischannel development, use, or research. Given Discipline-Conscious Researchers' strict focus on investigating agricultural communications as an academic discipline, it is possible they have not yet acknowledged the role social media play, and the role they will likely continue to play over time.

Finally, we labeled individuals who represented factor four Tech-Savvy Scholars because they agreed it is most important for research to focus on investigating technology in agricultural communications. Technology is a key component associated with the research themes they deemed second and third most important-agriculture and media relations/practices and visual literacy and/or visual communication. Tech-Savvy Scholars are likely visual learners and, therefore, visual researchers who have the technology skills necessary to create and design visual communications using various web-based platforms.

Technology in agricultural communications, a theme similar to one identified by Williams and Woods (2002), Miller et al. (2006), and Edgar et al. (2006), has not been a research priority over the past two decades as $n=8$ journal articles supported this theme. However, agriculture and media relations/practices has been a research priority $(n=30)$ and visual literacy and/or visual communication has as well ( $n=11$; Edgar et al., 2009; Miller et al., 2006; Williams \& Woods, 2002). Opposite from Message Framing Influencers, Tech-Savvy Scholars agreed investigating the effects of message framing on consumer perceptions and behaviors is the least important research theme within agricultural communications. Often, there is little technology associated with this type of research, which could be the reason they do not consider it a priority.

The consensus statements revealed that scholars in agricultural communications generally agreed that public perceptions/understanding of agriculture and natural resources was an important research theme, similar to one identified by Williford et al. (2016). Results from the content analysis similarly revealed that scholars have prioritized this area of research in the past two decades because it was the second most prevalent research we identified $(n=25)$. Agricultural communications scholars also generally agreed that investigating crisis communications in agricultural communications was important, however, only $n=3$ journal articles supported this theme. Therefore, although scholars believe it is important, it has not been a research priority in the past two decades, based on the criteria we established.

To no surprise, two of the three research themes that scholars generally agreed were not important-agricultural communications efforts during historical events $(n=5)$ and agritourism $(n=2)$ - have also not been research priorities. Remarkably, the third statement that scholars generally agreed was not important - the role of agricultural communications professional organizations $(n=10)$ - has been a research priority. 
One might assume the research theme agricultural communications scholars perceive to be most important is representative of the research they conduct themselves. However, we found that this is not always the case. Results indicate that $n=27(64.3 \%)$ scholars in the sample did conduct research that represented the research theme they deemed most important, whereas $n=15(35.7 \%)$ did not. Thus, it is important to acknowledge that the research topics most interesting or appealing to agricultural communications scholars is not always the research they consider to be most important to the discipline. It is also possible that agricultural communications scholars only conduct research that complements their skillset. Perhaps, they do not have the research skills or knowledge to contribute to the research theme they consider most important and, therefore, continue to work where they feel competent.

The research described herein reflects the scholarly base supporting agricultural communications based on an analysis of journal articles published in JAC between 2000 and 2019 and characterizes the four dominant viewpoints of agricultural communications scholars as of 2020. The study can serve as a seminal piece, being the first study of its kind to characterize agricultural communications scholars. It can also provide the foundation for future comparisons to determine how time influences the research themes prioritized in agricultural communications and scholarly perspectives about the importance of research. Scholars should continue to reflect upon the state of research in agricultural communications because doing so will enable us to improve the discipline's impact and monitor its progression collectively over time.

Additional research is also needed to further understand the viewpoints of agricultural communications scholars to predict the trajectory of research advancing the discipline. By further understanding the viewpoints of agricultural communications scholars, we can maximize collaborative efforts and determine how to capitalize on various skillsets. This would enable agricultural communications scholars to diversify research teams and grant teams and, perhaps, strengthen the quality of projects and grant proposals by strategically uniting individuals with differing research interests, experiences, and skillsets. A more in-depth understanding of these viewpoints would also allow for the strategic design and implementation of professional development sessions tailored toward various scholars in the discipline. For example, the present study identified the agricultural communications research topics that scholars perceived to be least and most important. With this information, scholars can propose workshops that introduce rigorous research methods or the integration of theoretical frameworks that might illuminate scholars' key interests in innovative ways.

Furthermore, we recommend scholars create a national research agenda specific to agricultural communications. A research agenda could broaden the academic and societal impact of agricultural communications by guiding and unifying scholarship to increase the depth of research instead of the breadth. It could also establish common goals scholars can work toward that aim to accomplish a shared vision for agricultural communications. By identifying characteristics of researchers who might use the agenda to guide their work, as achieved by the study described herein, scholars can create the agenda to center not only around priority issues but also around the types of researchers in the discipline. We assume that scholars can categorize themselves into one of the dominant viewpoints by examining the distinguishing statements associated with each and deciphering where they best fit. Therefore, if the agenda is created to highlight the interests of scholars who represent each viewpoint, then scholars will know where they are most expected to contribute to the agenda. If further research is conducted that identifies additional characteristics of researchers in agricultural communications, such as the dominant methodological skillet associated with each type, the expectations for scholars can be even more 
clearly communicated within the agenda. Similarly, the agenda could highlight where the triangulation of various researcher types would be most valuable to dissect the priority issue under investigation in unique and complementary ways.

\section{References}

Association for Communication Excellence. (n.d.) Centennial moments. https://aceweb.org/centennial-moments

Baker, L. M., \& King, A. E. H. (2017). Let's get theoretical: A quantitative content analysis of theories and models used in the Journal of Applied Communications. Journal of Applied Communications, 100(1), 51-63. https://doi.org/10.4148/1051-0834.1021

Boone, K., Meisenbach, T., \& Tucker, M. (2000). Agricultural communications: Changes and challenges. Iowa State University Press.

Borchelt, R. E. (2001). Communicating the future: Report of the research roadmap panel for public communication of science and technology in the twenty-first century. Science Communication, 23(2), 194-211. https://doi.org/10.1177/1075547001023002006

Brown, S. R. (1993). A primer on Q methodology. Operant Subjectivity, 16(3), 91-138. https://www.researchgate.net/profile/Steven_R_Brown/publication/244998835_A_Primer _on_Q_Methodology/links/54749d440cf2778985abeb8e/A-Primer-on-QMethodology.pdf

Brown, S. R. (1995). Q methodology as the foundation for a science of subjectivity. Operant Subjectivity, 18, 1-16. http://www.operantsubjectivity.org/col/1

Brouwer, M. (1999). Q is accounting for tastes. Journal of Advertising Research, 39(2), 35-39. http://web.a.ebscohost.com.srvproxy1.library.tamu.edu/ehost/pdfviewer/pdfviewer?vid=1\&sid=3d19acc9-57e8-4f27b7a9-c6bf5a91a1a1\%40sdc-v-sessmgr01

Cannon, K. J., Specht, A. R., \& Buck, E. B. (2016). Agricultural communications programs: A national portrait of undergraduate courses. Journal of Applied Communications, 100(1), 22-32. https://doi.org/10.4148/1051-0834.1018

Cartmell, D. D., \& Evans, J. F. (2013). Understanding whence we came: Role of the association for communication excellence in the development of agricultural communications during the past century - and future implications. Journal of Applied Communications, 97(2), 50-70. https://doi.org/10.4148/1051-0834.1120

Corder, J., \& Irlbeck, E. (2018). Agricultural communications skills, abilities and knowledge desired by employers compared to current curriculum: A literary review. Journal of Agricultural Education, 59(4), 177-193. https://doi.org/10.5032/jae.2018.04177 
Creswell, J. W., \& Miller, D. L. (2000). Determining validity in qualitative inquiry. Theory into Practice, 39(9), 124-130. https://doi.org/10.1207/s15430421tip3903_2

Creswell, J. W., \& Poth, C. N. (2018). Qualitive inquiry and research design (4th ed.). SAGE Publications, Inc.

Data, USA. Agricultural communication and journalism. https://datausa.io/profile/cip/agricultural-communication-journalism

Del Mol, J., \& Buysse, A. (2008). Understanding of children's influence in parent-child relationships: A Q methodological study. Journal of Personal and Social Relationships, 25(2), 359-379. https://doi.org/10.1177/0265407507087963

Dennis, K. E. (1992). Commentary: Looking at reliability and validity through Q-colored glasses. Operant Subjectivity, 16, 37-44. http://www.operantsubjectivity.org/col/1

Doerfert, D., \& Cepica, M. (1991). The current status of agricultural communications/journalism programs in the United States [Unpublished manuscript]. Center for Agricultural Technology Transfer, Texas Tech University.

Doerfert, D., Evans, J., Cartmell, D., \& Irani, T. (2007). Developing an international framework and agenda for agricultural communications research. Journal of Applied Communications, 91(3), 7-16. https://doi.org/10.4148/1051-0834.1245

Doerfert, D. L. (2011). National research agenda: American Association for Agricultural Education's research priority areas for 2011-2015. Department of Agricultural Education and Communications, Texas Tech University.

Doerfert, D. L. (2003). Skate to where others are heading. Journal of Applied Communications, 87(4), 39-41. https://agris.fao.org/agris-search/search.do?recordID=US201300937455

Duncan, C. H. (1957). An evaluation of the agricultural journalism curriculum in land grant colleges [Unpublished master's thesis]. University of Missouri.

Edgar, L., Rutherford, T., \& Briers, G. (2009). Research themes, authors, and methodologies in the Journal of Applied Communications: A ten-year overview. Journal of Applied Communications, 93(1-2), 21-34. https://doi.org/10.4148/1051-0834.1201

Evans, J. F. (2006). Roaming the changing theoretical landscape of agricultural communications. Journal of Applied Communications, 90(1), 15-32. https://doi.org/10.4148/1051-0834.1288

Glaser, B. (1965). The constant comparative method of qualitative analysis. Social Problems, 12(4), 436-445. https://doi.org/10.1525/sp.1965.12.4.03a00070 
Guttman, L. (1954). Some necessary conditions for common-factor analysis. Psychometrika, 19(2), 149-161. https://doi.org/10.1007/BF02289162

Irani, T., \& Doerfert, D. L. (2013). Preparing for the next 150 years of agricultural communications. Journal of Applied Communications, 97(2), 6-13. https://doi.org/10.4148/1051-0834.1109

Irlbeck, E., \& Buck, E. B. (2017). Are we there yet? Toward an agricultural communications academic organization. Journal of Applied Communications, 101(3), 1-7. https://doi.org/10.4148/1051-0834.1838

Jordan, K., Capdevila, R. \& Johnson, S. (2005). Baby or beauty: A Q study into post pregnancy body image. Journal of Reproductive and Infant Psychology, 23(1), 19-31. https://doi.org/10.1080/02646830512331330965

Kaiser, H. F. (1970). A second generation little jiffy. Psychometrika, 35(4), 401-417. https://doi.org/10.1007/BF02291817

Killam, L., Timmermans, K. E., \& Raymond, J. M. (2013). The barriers to and benefits of conducting Q-sorts in the classroom. Nurse Researcher, 21(2), 24-29. https://doi.org/10.7748/nr2013.11.21.2.24.el210

Knight, J. A. (1984). A content analysis of The Agricultural Education Magazine, 1929-1984 [Conference proceeding]. The 15th National Agricultural Education Research Meeting, New Orleans, LA, United States.

Kurtzo, F., Hansen, M. J., Rucker, K. J., \& Edgar, L. D. (2016). Agricultural communications: Perspectives from the experts. Journal of Applied Communications, 100(1), 33-45. https://doi.org/10.4148/1051-0834.1023

Leggette, H. R., \& Redwine, T. (2016). Using Q methodology in agricultural communications research: A philosophical study. Journal of Applied Communications, 100(3), 57-67. https://doi.org/10.4148/1051-0834.1230

Lincoln, Y. S., \& Guba, E. G. (1985). Naturalistic inquiry. SAGE Publications, Inc.

Lombard, M., Snyder-Duch, J., \& Bracken, C. C. (2002). Content analysis in mass communication: Assessment and reporting intercoder reliability. Human Communication Research, 28(4), 587-604. https://doi.org/10.1111/j.1468-2958.2002.tb00826.x

McKeown, B., \& Thomas, D. (1988). Q methodology. SAGE Publications, Inc.

McTavish, D. G., \& Pirro, E. B. (1990). Contextual content analysis. Quality and Quantity, 24, 245-265. https://doi.org/10.1007/BF00139259 
Miller, J. D., Large, M. M., \& Rucker, K. L. (2015). Characteristics of U.S. agricultural communications undergraduate programs. Journal of Applied Communications, 99(4), 76-90. https://doi.org/10.4148/1051-0834.1063

Miller, J. D., Stewart, D. M., \& West, L. M. (2006). Themes, authors, and citations in the Journal of Applied Communications, 2000-2004 [Paper presentation]. Southern Association of Agricultural Scientists - Agricultural Communications Section Meeting. Orlando, FL, United States.

Mohammed, J. A. (2020). The role of radio in promoting agricultural development: A case study of National Agricultural Extension and Research Liason [sic] Services (NAERLS) Zaria. NTAtvc Journal of Communication, 4(1), 92-98. https://www.researchgate.net/profile/MohammedAldossary/publication/340037729_Oral_HealthRelated_Quality_of_Life_in_Children_Assessment_Tools_at_a_Glance/links/5e73b9784 58515c677c30fe2/Oral-Health-Related-Quality-of-Life-in-Children-Assessment-Toolsat-a-Glance.pdf

Montemayer, G. J. S., Navarro, M. J., \& Navarro, K. I. A. (2020). Philippines: From science then communication to science communication. In T. Gascoigne, B. Schiele, J. Leach, M. Riedlinger, B. V. Lewenstein, L. Massarani, \& P. Broks (Eds.), Communicating science: A global perspective (pp. 665-692). Australian National University Press. https://doi.org/10.22459/CS.2020

Morgan, A. C. (2012). Competencies needed by agricultural communication undergraduates: A focus group study of alumni. Journal of Applied Communications, 96(2), 17-29. https://doi.org/10.4148/1051-0834.1146

Naile, T. L., Robertson, J. T. \& Cartmell, D. D. II. (2010). Examining JAC: An analysis of the scholarly progression of the Journal of Applied Communications. Journal of Applied Communications, 94(1), 49-60. https://doi.org/10.4148/1051-0834.1186

Osborne, E. W. (n.d.). National research agenda: Agricultural education and communication, 2007-2010. Department of Agricultural Education and Communication, University of Florida.

Patton, M. Q. (2002). Qualitative research and evaluation methods (3rd ed.). SAGE Publications, Inc.

Polit, D. F., \& Beck, C. T. (2010). Generalization in quantitative and qualitative research: Myths and strategies. International Journal of Nursing Studies, 47(11), 1451-1458. https://doi.org/10.1016/j.ijnurstu.2010.06.004

Preissle, J., \& deMarris, K. (2015). Teaching reflexivity in qualitative research. In N. K. Denzin $\&$ M. D. Giardina (Eds.), The Sage encyclopedia of qualitative research methods (pp. 845-846). SAGE Publications, Inc. https://doi.org/10.4135/9781412963909.n439 
Ramlo, S. E., \& Newman, I. (2011). Q methodology and its position in the mixed methods continuum. The International Journal of Q Methodology, 34(3), 172-191. https://www.researchgate.net/profile/SusanRamlo/publication/257942977_Q_Methodology_and_Its_Position_in_the_Mixed_Methods_Continuum/links/0046352668cc7f3329000000/Q-Methodology-and-ItsPosition-in-the-Mixed-Methods-Continuum.pdf

Reisner, A. (1990). An overview of agricultural communications programs and curricula. Journal of Applied Communications, 74(1), 8-17. https://doi.org/10.4148/1051-0834.1508

Roberts, T. G., Harder, A., \& Brashears, M. T. (2016). American Association for Agricultural Education national research agenda: 2016-2020. Department of Agricultural Education and Communication, University of Florida.

Roberts, O., \& Evans, J. (2015). Tackling structure and format - The 'great unknown' in professional blogging. Journal of Applied Communications, 99(2), 6-14. https://doi.org/10.4148/1051-0834.1044

Rodriguez, L., \& Evans, J. F. (2016). Coming of age: How JAC is reflecting a national research agenda for communications in agriculture, natural resources, and life human sciences. Journal of Applied Communications, 100(1), 29-50. https://doi.org/10.4148/1051-0834.1020

Simon, L., Robertson, T., \& Doerfert, D. (2003). The inclusion of risk communications in the agricultural communications curriculum: A pre-assessment of need [Paper presentation]. American Association for Agricultural Education Western Region, Portland, Oregon, United States.

Spearman, C. (1937). Abilities as sums of factors, or as their products. Journal of Educational Psychology, 28(8), 629-631. https://doi.org/10.1037/h0056483

Stephen, T. D. (1985). Q-methodology in communication science: An introduction. Communication Quarterly, 33(3), 193-208. https://doi.org/10.1080/01463378509369598

Tucker, M., Whaley, S. R., \& Cano, J. (2003). Agricultural education and agricultural communications: Striking proper balance in the academy. Journal of Agricultural Education, 44(1), 22-30. https://doi.org/10.5032/jae.2003.01022

Valenta, A. L., \& Wigger, U. (1997). Q-methodology: Definition and application in health care informatics. Journal of the American Medical Informatics Association, 4(6), 501-510. https://doi.org/10.1136/jamia.1997.0040501

Van Exel, N. J. A., \& de Graaf, G. (2005). Q methodology: A sneak preview. www.jobvanexel.nl 
Watts, S. (2011). Subjectivity as an operant: A conceptual exploration and discussion. The International Journal of Q Methodology, 35(1), 37-47. http://citeseerx.ist.psu.edu/viewdoc/download?doi=10.1.1.967.2988\&rep=rep1\&type=pdf

Watts, S., \& Stenner, P. (2012). Doing Q methodological research: Theory, method \& interpretation. SAGE Publications, Inc.

Whiting, L. R. (2002). An opinion: Trends that I hope are only trendy. Journal of Applied Communications, 86(1), 51-54.

Williams, R. A. \& Woods, M. D. (2002). A synthesis of agricultural communication research published in the Journal of Applied Communications from 1992-2001 [Paper presentation]. Agricultural Communicators in Education International Conference, Savannah, GA, United States.

Williford, B., Edgar, L. D., Rucker, K. J., \& Estes, S. (2016). Literature themes from five decades of agricultural communications publications. Journal of Applied Communications, 100(1), 64-75. https://doi.org/10.4148/1051-0834.1022

Wratten, S., Eccleston, C., \& Keogh, E. (2019). Perceptions of gendered and ungendered pain relief norms and stereotypes using Q-methodology. Pain, 160(2), 395-406. https://doi.org/10.1097/j.pain.0000000000001409

Zumalt, J. (2007). Identifying core periodical literature of the Agricultural Communications Documentation Center. Journal of Agricultural \& Food Information, 8(3), 43-63. https://doi.org/10.1300/J108v08n03_05 